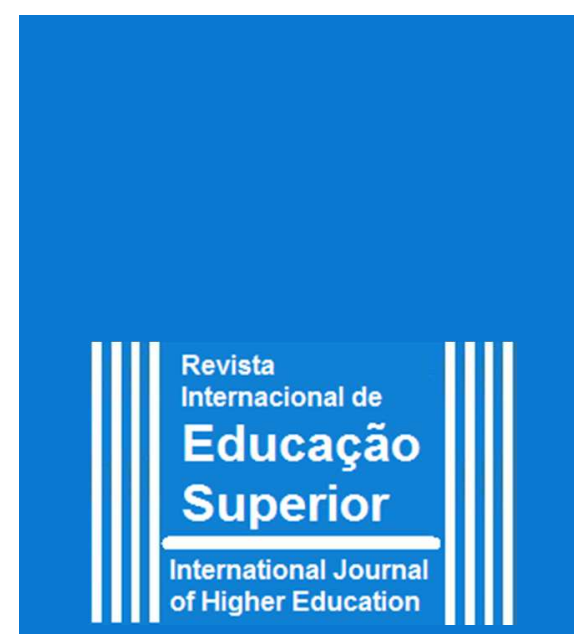

Os editores

Maria de Lourdes Pinto de Almeida José Camilo Filho

Publicado: 28 abr. 2020

doiz 10.20396/riesup.v6i08659498

e-location: e020046

ISSN 2446-9424

Checagem Antiplagiarismo

turniting]

Distribuido sobre

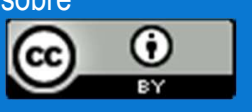

\section{Internacionalização da Educação Superior}

É com imenso prazer que apresentamos o volume 06 (seis) da nossa Revista Internacional de Educação - RIESup, ano de 2020. Temos 24 (vinte e quatro) artigos, 03 (três) resenhas, 13 (treze) relatos de pesquisa e 05 (cinco) relatos de experiência. Abrindo a seção "Artigos, temos Claudia Regina Baukat Silveira Moreira e Paulo Vinícius Baptista da Silva debatendo "Ações afirmativas fazem diferença? Uma análise dos perfis dos aprovados no vestibular da UFPR (2013-2017)". Os autores analisam os impactos da Lei n.12.711/2012 sobre os perfis dos aprovados no vestibular da Universidade Federal do Paraná entre 2013 e 2017, partindo da comparação com o Plano de Metas de Inclusão Social e Racial implementado pela instituição a partir de 2005. Foram analisados os microdados dos questionários socioeducacionais disponibilizados pelo Núcleo de Concursos da UFPR além dos perfis dos matriculados entre 2005 e 2012. Como resultado os autores afirmam que embora a Lei de Cotas tenha secundarizado a questão racial, no caso da UFPR foi mais efetiva na inclusão de Pretos, Pardos e Indígenas que o Plano de Metas Anterior.

Na sequência, Adilson Luiz Tiecher, Danielle da Motta Fialho e Romilda Teodora Ens abordam "Formações do professor para a educação superior em eventos nacionais (2014-2016)", tema de extrema relevância neste cenário de preocupação com a Educação Básica, decorrente das orientações políticoeconômicas das organizações multilaterais a que se submetem os países Latinos Americanos. O objetivo foi analisar, por meio do "Estado da Arte", a produção científica que focaliza a formação de professores para a Educação Superior em cinco eventos da área de Educação no Brasil (ANPAE 2015, ANPEd 2015, ANPEd SUL 2014 e 2016 e EDUCERE 2015). Com base neste levantamento de dados os autores da pesquisa fizeram uma reflexão tendo como aportes teóricos pesquisadores do tema, bem como documentos legais, como a LDB (1996) e o PNE (2014), (dentre outros). Segundo os autores, os resultados indicam que a formação de professor deve possibilitar uma formação que os prepare para realizarem análises críticas e reflexivas de sua prática e do próprio contexto em que atuam (Educação Superior). 
Glaucia Muñoz dos Reis e Maria de Fátima Ramos de Andrade nos apresentam "As parcerias informais e o desenvolvimento profissional docente no ensino superior", cujo objetivo foi analisar como estas, no contexto da universidade, colaboram no desenvolvimento profissional dos docentes. Os autores fizeram um estudo qualitativo por meio da aplicação de entrevistas semiestruturadas com nove professores do curso de Pedagogia de quatro universidades. Baseados nos dados qualitativos levantados, os pesquisadores constataram que as parcerias informais e por afinidade têm influenciado, de maneira preponderante, o desenvolvimento pessoal e profissional, trazendo trocas materiais e imateriais, novas maneiras de se trabalhar, novos olhares a partir da percepção do parceiro docente.

Dando continuidade à discussão do tema da internacionalização na universidade La Salle, Silvia Adriana da Silva Soares, Evaldo Luis Pauly e Paulo Fossatti, analisam o papel das/os "secretárias/os de programas de pós- graduação stricto sensu e sua relação com a internacionalização". O artigo tem como objetivo analisar a importância do desenvolvimento de competências das/os secretárias/os de Programa de Pós-graduação stricto sensu voltadas à internacionalização, em específico ao domínio de língua estrangeira. Como resultado desta investigação, os autores recomendaram que as Instituições de Educação Superior voltem seus olhares para dentro das secretarias, investindo em formação, para preparar o pessoal que já faz parte de seus quadros funcionais a atender aos visitantes estrangeiros, suprindo o que é necessário para o domínio da língua estrangeira.

Pedro Luis Saraiva Barbosa, Roberta da Silva e Rafaella Alves de Sousa discutem, na sequência, a "Compreensão do uso de desenhos no processo de ensino aprendizagem para alunas do curso informatização", resultado de um Projeto desenvolvido no âmbito do Instituto Federal de Educação, Ciência e Tecnologia do Ceará (IFCE) - Campus Cedro denominado "InformatizAção" que se materializa com a oferta de um curso específico para o público feminino na área de informática básica e também a inclusão digital dessas mulheres. O públicoalvo do curso são mulheres com idade superior a 40 anos, que se encontram em momento de vulnerabilidade digital e que residem na cidade de Cedro - CE. Este texto é fruto de uma pesquisa que teve por objetivo compreender como a utilização de desenhos - em um processo de abstração de conteúdos na disciplina de Informática - pode auxiliar no ensino- aprendizagem das mulheres participantes do curso de extensão. Vale a pena conferir!

Juliane Ines Di Francesco Kich nos brinda com um artigo sobre "Blended learning na prática: o caso do Curso Superior de Administração do Centro Universitário Estácio de Santa Catarina", que teve por objetivo analisar a implantação do Blended Learning no curso presencial de graduação em Administração, do Centro Universitário Estácio de Santa Catarina, realizado pelo método de sala de aula invertida, com base na percepção de seus discentes, docentes e gestores, no primeiro semestre letivo de 2018. Para a autora, os resultados evidenciam que os alunos possuem opiniões bastante divergentes quanto à aplicação do novo método de ensino, alguns mostrando-se favoráveis e outros completamente contra, enquanto os docentes, apesar de resistentes à mudança no princípio, acreditam mais na eficácia do novo método. Além disso, denota-se, segundo Juliane, que o apoio dos gestores tem sido essencial 
para que a implantação do Blended Learning aconteça, embora, tenham percebido a necessidade de desacelerar o processo de mudança e torná-lo mais gradativo.

Géssica Priscila Ramos, José Carlos Rothen e Maria Cristina da Silveira Galan Fernandes debatem os "Mecanismos de avaliação e regulação da Universidade Federal Brasileira no REUNI". O Programa de Apoio a Planos de Reestruturação e Expansão das Universidades Federais(REUNI), instituído em 2007, teve como objetivo central expandir o acesso e a permanência na educação superior, com base em contrato estabelecido entre o Ministério da Educação (MEC) e a Universidade Federal com a definição das condições necessárias à ampliação física, acadêmica e pedagógica da rede federal. Como resultado os autores notaram que, embora o processo de adesão ao Programa tenha sido voluntário pela unidade, a ação do MEC na Universidade pelo Reuni foi invasiva, ferindo sua autonomia nas dimensões política, financeira e acadêmica. Todavia, não obstante os mecanismos de avaliação e regulação presentes no Reuni, para os autores, as universidades federais brasileiras compactuaram com o princípio da democratização do ensino superior e, por isso, acabaram por se sujeitar a tais mecanismos para conseguir financiamento para materializá-lo. Vale a pena uma reflexão, confiram!

Filinto Jorge Eisenbach Neto e Lindomar Wessler Boneti analisam o "Sistema econômico internacional, ideologia e ensino superior brasileiro", com o objetivo de desenvolver uma reflexão teórica acerca do papel do sistema econômico internacional e da ideologia na formação de um modelo do ensino superior no Brasil atrelado às expectativas do mundo produtivo. Tratase, segundo os autores, de um processo de "coisificação" institucional. Metodologicamente, os pesquisadores examinaram a institucionalidade educacional na LDB e na BNCC (Base nacional comum curricular), assim como os referenciais do advento do modelo econômico internacional e da ideologia como estratégia de consolidação dos preceitos deste modelo. Como resultado, os autores concluíram que o sistema econômico internacional, capitaneado pelo poder ideológico, constitui-se como um fator expressivo no aparecimento do "mercado de trabalho" como fim do processo de ensinar, especialmente no sistema de ensino superior privado. Porém, consideraram também que o processo da "coisificação" inerente ao sistema de ensino, se encontra em algo mais complexo que se agrega a este processo como é o caso, por exemplo, da meritocracia que se constitui no principal fator ideológico e de valorização da individualidade e do ato de fazer em detrimento, respectivamente, da coletividade e do pensar.

Milena Cristina de Freitas e Claudia Aranha Gil fazem uma reflexão sobre o "Envelhecimento e trabalho: percepções e vivências de docentes do ensino superior na maturidade", fruto de uma pesquisa que objetivou compreender as concepções de docentes do Ensino Superior na maturidade sobre a relação entre envelhecer e trabalhar. Segundo as autoras, a coleta dos dados baseou-se na técnica do estudo de caso múltiplo, e observou-se que os professores associaram diferentes percepções de envelhecimento ligadas às perdas e ganhos, demonstrando uma estreita relação entre o trabalho docente e o prazer e a possibilidade de contribuir para uma construção de sociedade a melhor possível.

Samuel Pires Melo, Osmar Rufino Braga e Jullyane Frazão Santana na sequência discutem a "Juventude rural e ensino superior público: trajetórias de estudantes de um Campus 
Universitário Público do Nordeste do Brasil". Neste artigo os autores analisam a trajetória estudantil de jovens rurais de um campus universitário público do Nordeste do Brasil, numa amostra aleatória de estudantes dos cursos das áreas de ciências exatas e biológicas. $\mathrm{Na}$ pesquisa foram utilizados como instrumentos de coleta de dados um questionário elaborado pelos autores e um diário de campo. Os resultados, segundo os pesquisadores, apontaram para um perfil de jovens com idade que varia de 18 a 33 anos; trajetória escolar de migração para espaços citadinos, como motivação para continuar os estudos devido à precarização da educação nos espaços rurais; e perspectivas de futuro voltadas para o ensino superior objetivando a ascensão financeira para ajudar a família e seus territórios. Para os autores, esse estudo sugere que os programas de interiorização e expansão das universidades federais estão sendo um aliado nas trajetórias de mudanças dos jovens e das jovens das áreas rurais.

Franciele Siqueira Radetzke e Roque Ismael da Costa Güllich debatem "As pesquisas sobre a docência no ensino superior em contexto brasileiro: desafios para pensar a formação em ciências". A docência no Ensino Superior é a temática central do presente estudo que tem por objetivo apresentar um panorama acerca das concepções de docência universitária, bem como estabelecer diálogo com as principais temáticas investigadas em dissertações e teses brasileiras, da área de Ciências da Natureza e suas Tecnologias (CNT). Para tanto, foi realizada uma pesquisa de abordagem qualitativa de tipo bibliográfico baseada na busca de teses e dissertações sobre docência na educação superior na Biblioteca Digital de Teses e Dissertações (BDTD), do Instituto Brasileiro de Informação e Tecnologia (IBICT). As concepções recorrentes foram destacadas como Experiência (12:14), Pesquisa (5:14) e Naturalizada (2:14) e, dentre as temáticas mais investigadas, apareceram: Prática Docente (7:14), Identidade Profissional (6:14), Processos Formativos (2:14), Concepções de Docência (2:14) e Saberes Docentes (1:14). Foi possível perceber também que as temáticas e concepções investigadas relacionam-se no contexto da educação superior na tentativa de lograr entendimentos acerca do processo de ensinar e aprender. Da investigação emanou como principal desafio a necessidade de formação continuada sobre concepções e práticas docentes para aprimorar a atuação docente de professores da educação superior.

Gregório Durlo Grisa, Clarissa Eckert Baeta Neves e Leandro Raizer fazem uma reflexão sobre os "Percursos acadêmicos de estudantes cotistas: um estudo de caso à luz da equidade, raça e paridade participativa". A pesquisa investiga trajetórias de estudantes cotistas em uma Universidade Federal e analisa as razões para diferentes percursos acadêmicos, tendo por base um estudo de caso, com o uso de survey em três grupos de estudantes: evadidos, retidos e graduados. Segundo os autores, os resultados foram discutidos à luz dos conceitos de equidade de Hawls, de raça de Guimarães e de paridade participativa de Fraser, onde a falta de tempo para estudar é apontada como decisiva por estudantes com dificuldades em seus percursos. Para os autores, o apoio familiar e o trabalho são fatores determinantes do êxito acadêmico e as variáveis de gênero e raça são influentes no sucesso e no fracasso acadêmico.

Ricardo Luiz de Bittencourt e Renata Geremias da Silva debatem as "Contribuições da pesquisa para o desenvolvimento profissional docente na perspectiva dos coordenadores dos cursos de licenciatura". O presente artigo investiga as contribuições da pesquisa para o

\begin{tabular}{l|l|l|l|l|l} 
(C) Rev. Inter. Educ. Sup. & Campinas, SP & v.6 & $1-15$ & $\mathrm{e} 020046$ & 2020 \\
\hline
\end{tabular}


desenvolvimento profissional docente na perspectiva dos coordenadores dos cursos de Licenciatura, mediante uma pesquisa qualitativa tendo como base os cursos de Licenciatura de Pedagogia, Letras, Matemática, Geografia e História. Vale a pena conferir!

Ruy de Deus e Mello Neto, Hugo Augusto Vasconcelos Medeiros e Afrânio Mendes Catani vão refletir sobre o "ProUni e retornos de capitais para instituições privadas de ensino superior: uma leitura para além dos benefícios diretos com o financiamento público". O objetivo deste artigo foi analisar se, no caso específico dos cursos de Direito, existe a relação entre antecedentes de desvantagem e desempenho acadêmico, bem como se há retornos, além do capital econômico, para as Instituições Privadas de Educação Superior (IPES) em manter alunos ProUni. Para isso, foi criado, segundo os autores, um modelo de regressão linear com dados do Enade, usando como variável dependente a nota no exame, e como variáveis independentes a proporção de alunos ProUni no curso, o perfil socioeconômico médio da turma, e o perfil docente. Segundo os autores, a partir do modelo e da bibliografia especializada, observou-se que, nos cursos de direito, as IPES obtêm retornos consideravelmente amplos, tanto de capital econômico, em virtude da estrutura de financiamento da política pública, quanto de capital simbólico, pela relação positiva entre presença de alunos ProUni no curso e a nota no ENADE.

Samoara Viacelli da Luz e Herivelto Moreira vão nos brindar com uma discussão sobre a "A aquisição de habilidades didático-pedagógicas de professores do ensino superior", onde o objetivo foi identificar as atividades que mais contribuíram para a aquisição de habilidades didático-pedagógicas de professores dos cursos de graduação em Engenharia Civil, de Computação, Elétrica, Eletrônica e Mecânica em três campi de uma universidade pública do sul do Brasil. Os principais resultados, segundo os autores, mostram que a experiência adquirida no dia a dia consistiu na principal fonte de contribuição para a aquisição de habilidades didático-pedagógicas, apesar de a legislação brasileira prever que a preparação para a docência no ensino superior se efetive em cursos de Pós-graduação stricto sensu.

Kyria Rebeca Finardi, Felipe Furtado Guimarães e Ana Rachel Mendes, na sequência, escrevem sobre "Pensando a internacionalização (crítica) do ensino superior brasileiro", cujo objetivo foi refletir sobre a internacionalização das instituições de educação superior brasileiras de forma mais crítica a partir de uma meta-análise dos estudos de um grupo de pesquisa que aborda questões como programas de internacionalização e políticas linguísticas e de internacionalização neste contexto. Uma análise da meta-análise sugere uma brecha (ou desajuste) de princípios e políticas para guiar o processo de internacionalização de forma crítica no Brasil. A internacionalização crítica se aborda tendo em conta o papel de programas, políticas linguísticas e de internacionalização, bem como a partir do reconhecimento da mercantilização da educação e dos meios de combatê-lo. Para tanto, os autores propõem desconstrução do imaginário hierárquico de dominação intelectual e cultural e a interação solidária entre as instituições dos países periféricos para fortalecer o carácter de bem público da educação superior.

Joviles Vitório Trevisol e Sherlon Cristina De Bastiani vão refletir sobre "O cinquentenário da educação superior no oeste de Santa Catarina: dinâmicas e tendências (1968-

\begin{tabular}{l|c|c|c|c|c|} 
(C) Rev. Inter. Educ. Sup. & Campinas, SP & v.6 & $1-15$ & e020046 & 2020 \\
\hline
\end{tabular}


2018)", cujo propósito foi analisar os processos de interiorização da educação superior no Estado. Segundo os autores, as dinâmicas da expansão foram estudadas a partir de uma mesorregião específica (o Oeste), dado o fato de ser a maior entre as seis mesorregiões, correspondendo a um quarto do território estadual, composta por 118 municípios. O estudo foi desenvolvido entre agosto de 2015 a julho de 2017. Os dados quantitativos foram obtidos na base de dados do INEP e do IBGE e por meio da consulta aos às páginas eletrônicos das instituições de ensino superior pesquisadas. $\mathrm{O}$ estudo mostrou, segundo os autores, que a expansão foi impulsionada pelo setor privado. Em 2015, o segmento privado respondia por 80,9\% das IES que ofereciam matrículas presenciais - 45,5\% dos cursos em faculdades; $33,3 \%$, em universidades e $15,2 \%$, em institutos federais. No que tange às matrículas, $72,3 \%$ se encontravam, em 2015, nas IES presenciais (40.522) e 27,7\%, nos polos de EAD (18.358). O bacharelado é, segundo Trevisol e Bastiani, o grau acadêmico que concentra o maior número de matrículas na região, correspondendo a $65,5 \%$ do total. Esta pesquisa reflete a política governamental de educação superior do país nessas últimas décadas. Vale a pena conferir!

Rodrigo Barbosa e Silva e Vida Kamila Pinheiro da Conceição analisam "O comitê de ética em pesquisa como espaço de formação continuada do professor universitário". Este artigo é fruto de uma reflexão sobre o trabalho docente desenvolvido em um Comitê de Ética em Pesquisa, cujo objetivo foi destacar o eixo da pesquisa como um dos componentes da formação profissional para a docência no ensino superior por meio da avaliação ética de protocolos de pesquisa. Os autores concluíram que a eticidade perpassa pelos saberes pedagógicos constituídos também no processo de atuação e mediação docente no campo da pesquisa, haja vista, ser este o modelo de formação para o magistério de nível superior preconizado no Brasil.

$\mathrm{Na}$ sequência, Adilson Cristiano Habowski e Elaine Conte vão refletir sobre as "Reproduções de gênero pela cinematografia: caminhos à educação?", fruto de uma pesquisa que discute as ideologias históricas transmitidas pela cinematografia, e que, causam a perda de sentido, insensibilidade e o enrijecimento intelectual pela ausência de (auto)crítica. Assim, o presente estudo, de caráter hermenêutico, propõe, segundo os autores, olhar as concepções de gênero e sexualidade veiculadas pelo cinema, na tentativa de rever suas repercussões na experiência do pensar educacional. Nesse cenário marcado pela reprodutibilidade técnica, os autores evidenciam que há uma pequena resistência da indústria cinematográfica, que descortina paradigmas de gênero e sexualidade, evidenciando questões contemporâneas. A conclusão dos autores é que esses artefatos tecnológicos na educação precisam servir como impulsos para repensar a ação humana sob pena dos processos de ensino reproduzirem a exclusão, o desrespeito preconceituoso, uniformizador e insensível ao outro e à pluralidade de experiências. Para Habowski e Conte, trata-se de corrigir as deformações do reconhecimento por meio da reeducação que potencializa as diferenças humanas e o reconhecimento social.

José da Silva Santos Junior e Giselle Cristina Martins Real discutem o "Fator institucional para a evasão na educação superior: análise da produção acadêmica no Brasil". O objetivo do artigo foi analisar o cenário da produção de dissertações e de teses sobre a evasão na educação superior no período de 2000 a 2018, com vistas a identificar se e como o fator institucional foi apontado como um dos responsáveis por esse fenômeno nas Instituições de Educação Superior 
(IES) no Brasil. Para a busca de teses e dissertações, os autores recorreram à Biblioteca Digital de Teses e Dissertações (BDTD) do Instituto Brasileiro de Informação em Ciência e Tecnologia (IBICT) e ao Banco de Teses e Dissertações da Coordenadoria de Aperfeiçoamento de Pessoal de Nível Superior(Capes). Foram selecionadas 267 dissertações e 32 teses, em que se procedeu à análise dos títulos, dos resumos e das palavras-chave e, em alguns casos, a uma leitura transversal da introdução e das considerações finais dessas pesquisas sobre o tópico da evasão no período considerado. Posteriormente, foram identificados, nas mesmas fontes da pesquisa, 11 pesquisas sobre o fator institucional que foram lidas integralmente. O referencial teórico foi a perspectiva da integração do estudante, de Tinto (1975), e a Pedagogia da afiliação, de Coulon (2017). Os resultados, segundo os autores, mostraram a necessidade de mais pesquisas sobre este tema, haja vista que, há restrição de formulação de políticas institucionais para a redução da evasão, sendo oportunas as pesquisas que considerem o processo de institucionalização dessas ações nas IES brasileiras.

Elisabete Cerutti vai nos brindar com um artigo sobre "Tecendo saberes sobre as tecnologias assistivas para o sujeito surdo no ensino superior", que reflete sobre a educação dos sujeitos surdos no Ensino Superior e analisa o potencial do uso das tecnologias assistivas para esses candidatos específicos à educação superior. Esta pesquisa, de cunho bibliográfico, analisa como vem sendo regulamentada a acessibilidade do estudante surdo através de tecnologia assistiva no Ensino Superior e quais dessas regulamentações podem diminuir as barreiras comunicacionais entre ouvintes e surdos. A autora aborda a evolução das tecnologias, realizando uma reflexão sobre a inserção das mesmas no cotidiano, bem como, as principais regulamentações que amparam o cuidado com o sujeito surdo. Cerutti conclui que as tecnologias assistivas são instrumentos capazes de facilitar a comunicação entre os sujeitos e que, para haver a inclusão das pessoas surdas, precisamos romper as barreiras físicas, metodológicas e atitudinais, visando criar um ambiente nas Instituições de Educação Superior onde todos se sintam cidadãos com os mesmos direitos para se expressarem e terem acesso à construção do conhecimento profissional e pessoal.

Juliana Aparecida Gulka e Elaine Rosangela de Oliveira Lucas discutem o tema do "Papel educativo das bibliotecas universitárias: mapeamento de dificuldades e interesses de discentes da graduação e pós-graduação na realização de trabalhos acadêmicos". Este artigo objetivou apresentar as dificuldades de estudantes de graduação e pós-graduação na realização de trabalhos acadêmicos, bem como refletir sobre o papel educativo das bibliotecas universitárias. Tratou-se de uma pesquisa quali-quantitativa que se desenvolveu por meio de pesquisa bibliográfica e levantamento de dados. Utilizou-se um questionário com perguntas abertas e fechadas, aplicado em agosto de 2018 aos 85 participantes do grupo Bolsistas CAPES na mídia social Facebook. Segundo as autoras, foi possível entender a educação e a informação como indissociáveis, de modo que as bibliotecas universitárias podem desenvolver um papel educativo e de ensino-aprendizagem nesse contexto, apoiando a missão das universidades no ensino, na pesquisa e na extensão.

Camila Ferreira da Silva, Rodrigo de Macedo Lopes e Amurabi Oliveira analisaram "A agenda de pesquisa em sociologia da educação na pós-graduação brasileira". Seu artigo tomou 
esta interseção para análise e se propôs a dar continuidade ao debate acerca das especificidades da Sociologia Educacional brasileira. Para tanto, tomou como objeto de estudo a agenda de investigação dos programas de pós-graduação de Sociologia e de Educação que serviram de base para o mapeamento das linhas de pesquisa diretamente ligadas aos professores/pesquisadores credenciados/as que tiveram seus currículos escrutinados com vistas a mapear seus projetos de pesquisa em andamento.

Karen Graziela Weber Machado e Adriana Justin Cerveira Kampff tratam da "Educação Superior: as aprendizagens construídas por mestrandos e doutorandos em Educação durante o processo de internacionalização". O presente estudo visou analisar as aprendizagens construídas pelos estudantes de pós-graduação em Educação, mediante experiências desenvolvidas no processo de internacionalização, durante seus percursos de formação acadêmica. $\mathrm{O}$ estudo caracterizou-se como uma pesquisa qualitativa, com coleta de dados realizada através de questionário on-line, contendo questões fechadas e abertas, aplicado junto a mestrandos e doutorandos. Os dados coletados foram analisados por meio da técnica de Análise Textual Discursiva (ATD). Com este estudo, foi possível perceber, segundo as autoras, a relevância da internacionalização para os estudantes de pós-graduação, oportunizando o desenvolvimento de conhecimentos, habilidades e valores internacionais e interculturais, em consonância com as demandas atuais para viver e trabalhar num mundo cada vez mais interconectado.

Abrindo a seção "Relatos de Pesquisa", temos um debate sobre as "Avaliações em larga escala e educação especial: alguns pressupostos em questão”, de Karin Rank Liebl, Iana Gomes de Lima e Marialva Moog Pinto. Este artigo teve como objetivo apontar que o princípio da homogeneização/padronização que embasa as avaliações em larga escala e o princípio da diversidade que alicerça a inclusão de alunos com deficiência, são elementos contraditórios na prática educacional em diferentes etapas da educação. A partir da compreensão da temática de estudo, os autores consideraram que o sistema pedagógico não possui um discurso coerente sobre a inclusão de pessoas com deficiência, uma vez que sua legislação obriga determinadas ações que não são cumpridas pelo próprio sistema.

A pesquisa sobre "A evasão em disciplinas de cursos de graduação: fatores intervenientes", de Rosângela Fritsch, Ricardo Ferreira Vitelli e Cleonice Silveira Rocha, teve por objetivo identificar fatores intervenientes na evasão em disciplinas de cursos de graduação em uma instituição de educação superior privada comunitária. Como método, foram realizadas análises descritivas de informações coletadas em bancos de dados da instituição, bem como análise multivariada permitindo identificar um conjunto de fatores intervenientes na problemática da evasão. Como resultado da análise, foram identificados fatores de risco de natureza estrutural, fatores relacionados a dificuldades nas disciplinas e à escolha do curso. Os fatores que individualmente contribuem para a evasão são: média baixa na disciplina; ou percentual alto e médio de reprovação da turma; e a média de créditos concluídos pelo discente, ou seja, quanto mais créditos no início do curso, maior a chance de evasão. É possível concluir que a evasão se relaciona significativamente com percursos de insucessos escolares, 
especialmente de reprovações indicando seu impacto negativo nos estudantes de classes menos favorecidas social e culturalmente e nos macroprocessos de exclusão social.

Na sequência, Lorena Peterini Marquezan e Cristiano Lanza Savegnago discutem o tema do "mestrado profissional no contexto da formação continuada e o impacto na atuação dos profissionais da educação". Esta pesquisa objetivou avaliar os resultados alcançados pelo Mestrado Profissional em Políticas Públicas e Gestão Educacional (PPPG) da Universidade Federal de Santa Maria (UFSM), no sentido de identificar a percepção dos egressos das turmas 2015 e 2016 sobre os impactos dessa formação na vida profissional e acadêmica, bem como dos produtos educacionais e/ou conhecimentos construídos e implementados nas instituições a que estão vinculados profissionalmente. Como método, foi realizado, segundo os autores, um estudo quanti-qualitativo com treze egressos do PPPG da UFSM, por meio de questionário semiaberto. Os resultados foram analisados qualitativamente e evidenciaram que esse curso se constitui potencializador de mecanismo de formação continuada aos seus egressos, pois possibilitou a ampliação, construção e [re]significação de conhecimentos profissionais e acadêmicos. No entanto, há indicativos de que a implementação dos produtos educacionais, ainda que satisfatória, poderá ser aprimorada mediante maior articulação e interlocução entre os atores e cenários educacionais envolvidos nesse processo.

Klinger Teodoro Ciríaco e Adriana Correa da Silva nos brindam com uma discussão sobre "Entre 'sobrevivência' e 'descoberta': a professora iniciante no ciclo de alfabetização", cujo objetivo da investigação reside em caracterizar elementos constitutivos da identidade profissional, bem como descrever os desafios da prática pedagógica. O referencial teórico contempla quesitos ligados à formação de professores, início da carreira e a prática de alfabetização na perspectiva do letramento A abordagem metodológica foi de natureza qualitativa, de caráter descritivo-analítico e os dados foram coletados mediante um instrumento de observação em sala de aula e um roteiro de entrevista semiestruturado. Considerando os objetivos e fundamentos deste estudo, é possível afirmar, segundo os autores, que o cruzamento das informações coligidas possibilitou realizar uma análise a partir de como a professora organiza suas práticas e, ao mesmo tempo, vai se formando docente ao ensinar a ler e escrever. Os dados ainda revelaram que os primeiros anos de docência são fundamentais para a construção da identidade, sendo essencial muita dedicação e comprometimento para desenvolver suas habilidades no processo de alfabetização e se estabilizar na carreira. Além disso, no caso pesquisado, observou-se ainda que a professora constitui sua prática a partir de experiências das quais participou enquanto aluna da Educação Básica, o que dificulta o trabalho com a heterogeneidade em sala de aula, como também deixa marcas negativas em relação ao alfabetizar, uma vez que, ao que tudo indica, parece existir uma prática de que se aprende a ler e escrever copiando as informações transmitidas

Isabel Izquierdo e Olga Nelly Estrada debatem as "Experiências de migração de acadêmicas sul-americanas para duas universidades públicas mexicanas". O objetivo desta pesquisa foi analisar as experiências de migração de acadêmicas sul-americanas, chegada e incorporação em duas Universidades Mexicanas, sendo uma delas no centro-sul e outra no noroeste do país. As autoras partiram do pressuposto de que no processo migratório as 
acadêmicas adquiriram uma série de experiências que lhes permitiram colocar em prática estratégias para transitar de situações de tensão a uma aprendizagem em todo o processo. $\mathrm{O}$ método utilizado para desenvolver esta pesquisa foi o biográfico, por meio relatos de vida, entrevistando as acadêmicas de países sul-americanos. Os dados mostraram que as acadêmicas desenvolveram estratégias de mimetização, criatividade, pragmatismo e perseverança, apesar das diferenças de desenvolvimento socioeconômico dos estados e do desenvolvimento nas investigações das universidades públicas onde trabalham.

Na sequência, Sergio Ricardo Quiroga debate a questão dos "Alunos e internacionalização: mobilidade estudantil nos processos de internacionalização", abordando as percepções de "participação", "ficar", "experiência" e "cultura" de estudantes da Universidade Nacional de San Luis (UNSL) que participaram da experiência de mobilidade acadêmica nas universidades colombianas, chilenas e mexicanas durante o período 2005-2014. Por meio de entrevistas, foram coletados os depoimentos de quatro estudantes que tiveram experiências de internacionalização e que viajaram para centros universitários estrangeiros. A experiência de mobilidade é enriquecedora para os estudantes e para sua futura vida profissional. A experiência de mobilidade, segundo o autor, é muito forte e poderosa em todas as pessoas e mais estudantes que aspiram a desenvolver uma carreira no futuro. Assim, a formação é enriquecida com esses aprendizados em diferentes contextos envolvendo uma experiência cognitiva e cultural.

Raquel Silveira da Silva e Tanise Paula Novello discutem "O uso das tecnologias digitais no ensinar matemática: recursos, percepções e desafios”. As autoras utilizaram um recorte de pesquisa realizado com estudantes da Universidade Federal do Rio Grande -FURG, cursando a Licenciatura em Matemática e matriculados na disciplina de Tecnologias Aplicada à Educação Matemática I. No decurso da disciplina, em uma das atividades os discentes conversaram com doze professores de escolas públicas sobre o seu fazer pedagógico e a presença das tecnologias digitais nos espaços de atuação e produziram relatórios, com o objetivo de compreender a ação pedagógica dos professores de Matemática da Educação Básica atrelada ao uso das tecnologias digitais. A partir dos registros gerados para análise, os pesquisadores utilizaram a técnica de Análise Textual Discursiva (ATD) a fim de compreender o fenômeno investigado através dos discursos produzidos. Neste estudo, foram discutidas três categorias que emergiram da ATD: recursos utilizados pelos docentes, percepções sobre o uso das tecnologias digitais(TD) e desafios no ensino de matemática. A partir dessas três categorias, percebeu-se que os principais recursos utilizados pelos docentes entrevistados têm sido o livro didático e a internet para pesquisa de conceitos. Dentre as principais percepções e desafios está a formação continuada voltada para o uso das tecnologias digitais. Como resultado, as autoras afirmam que se faz necessário repensar os recursos utilizados em sala de aula, bem como criar alternativas que atendam às necessidades dos sujeitos envolvidos e imersos em uma cultura tecnológica e assim contribuir para mudanças significativas na atuação docente no cenário atual.

Tatiane Peratz e Angela Maria Silveira Portelinha, na sequência, analisam "A organização do trabalho pedagógico no Instituto Federal e as implicações para o trabalho 
docente". O artigo resultou da pesquisa de mestrado cuja temática foi a organização do trabalho pedagógico (OTP) do Instituto Federal do Paraná (IFPR) e teve como objeto o trabalho docente, especificamente no referente às implicações da OTP. Buscou analisar as implicações da OTP para o trabalho docente e a formação no IFPR -Campus Palmas, na região sudoeste do Estado do Paraná. A metodologia baseia-se em pesquisa bibliográfica cotejada com análises de documentos e com as respostas de 24 docentes da instituição a um questionário. Nas análises, destaca-se a categoria verticalização do ensino como a principal implicação para o trabalho docente e formação, uma vez que essa forma de organização do ensino requer a atuação nos distintos níveis da educação -básica e superior. Contudo, ao mesmo tempo que a verticalização é apontada como uma implicação para o trabalho docente, é também considerada uma oportunidade de aprendizado para esse docente, visto que alternar entre os níveis da educação exige um constante desenvolvimento e disto emergem as necessidades formativas. As discussões revelam, segundo as autoras, contradições no tocante à OTP, ao trabalho docente e à formação para atuar na educação profissional.

Liliane Honorato Gonçalves e Débora Carneiro Zuin escrevem sobre "O sistema de saúde na assistência estudantil da Universidade Federal de Viçosa (UFV): a percepção dos estudantes de graduação beneficiados pelo PNAES" Nessa pesquisa, o autor buscou conhecer a percepção dos estudantes com este perfil em relação à assistência à saúde recebida em uma instituição federal de educação superior (Universidade Federal de Viçosa/ UFV). A técnica de coleta de dados foi o grupo focal realizado com os representantes da Comissão de Moradias Estudantis (CME) da UFV. Quantos aos resultados da pesquisa, foi alcançado o objetivo de conhecer a percepção dos estudantes sobre a assistência estudantil em geral e, em especial, em relação à assistência à saúde, além de descobrir seus anseios e queixas. Gonçalves e Zuin afirmam que, apesar de possuir uma abrangente Assistência Estudantil, a UFV não consegue atender a todas as demandas existentes e necessita de maior envolvimento com os estudantes para que ocorra maior participação destes, tanto nas decisões de ações quanto no planejamento da utilização de recursos.

Carlos Estrela Brito, Marcos Ferasso e Sandra Manuel Periedes Pereira Lopes Estrela Brito analisam "A gestão dos cursos EAD em Moçambique". Seu objetivo foi apresentar como a educação à distância (EAD) se tornou um objetivo nacional do governo do país para assegurar o acesso a um número cada vez maior de cidadãos e de melhorar a qualidade dos serviços prestados em todos os níveis e tipos de ensino. Caracterizada como estudo de caso, a pesquisa apresenta como principal resultado o fato de que a EAD é considerada uma das alternativas para atender as diferentes necessidades de formação superior face às evidentes dificuldades enfrentadas por Moçambique no quesito formação em nível superior. Segundo os autores, o Instituto Superior de Ciências e Educação à Distância (ISCED) contribui para o processo de elaboração de cursos a distância que se traduzem no desenvolvimento de um ambiente para suporte ao processo ensino-aprendizagem apoiado pelas novas tecnologias de informação e de comunicação, pressupondo um cuidadoso planejamento, que aponta para a necessidade de um enfoque sistêmico na produção de cursos, envolvendo uma equipe multidisciplinar, com habilidades e conhecimentos especializados. Para os autores, o enfoque sistêmico de 
concepção, produção e implementação de programas à distância está garantindo a realização do objetivo nacional do governo.

Fernando Bernardes Martins, Hugo Paula Almeida da Rocha e Felipe Rodrigues da Costa apresentam "Uma revisão narrativa sobre o estudante-atleta no ensino superior: barreiras, soluções e uma transição pós-carreira esportiva satisfatória”. Este estudo teve como objetivo analisar a conciliação entre esporte e formação acadêmica de estudantes-atletas na educação superior. Os autores pesquisaram no Portal da Capes e selecionaram 14 artigos para análise após refinamento. Observaram que estudantes-atletas encontram diferentes barreiras relacionadas ao estereótipo de inferioridade intelectual atribuída a eles, à sua rotina de treinamento e à preparação para a vida após o esporte. $\mathrm{O}$ incentivo às metas acadêmicas e o entendimento das instituições de ensino sobre as dificuldades encontradas pelos estudantesatletas foram apontados como meios de superar as barreiras relacionadas ao estereótipo negativo. Para Marins, Rocha e Costa, a participação em atividades que promovem o desenvolvimento profissional e a oferta de cursos on-line durante os períodos de preparação para competições são indicadas como uma estratégia para a transição de carreira pós-esporte satisfatória. Os autores concluíram levantando perguntas e sugestões para que a dupla carreira possa ser entendida como uma oportunidade efetiva para a formação de atletas de elite.

Leonardo Carnut e Raquel Aparecida de Oliveira nos brindam com um trabalho sobre "Educação política nas bases de dados da área da saúde: uma revisão integrativa". O objetivo deste texto foi o de revisar a literatura científica mundial indexada em bases de dados na área da saúde sobre o conceito de educação política. Os autores fizeram uma revisão integrativa teórica, orientada pela captura do conceito de educação política e dos elementos teóricoeducacionais que embasam esse conceito. A busca na literatura especializada foi realizada nos portais da Biblioteca Virtual em Saúde(BVS) do Centro Latino-americano e do Caribe de Informação em Ciências da Saúde (Bireme) e da Biblioteca Nacional de Medicina do Instituto Nacional de Saúde (National Institute of Health) dos Estados Unidos (PubMED) e nas bases de dados Web of Science e SCOPUS. Como resultado da pesquisa, constatou-se que a maior parte dos artigos indexados e incluídos (17) foi encontrada na BVS $(65,4 \%)$ e $61,5 \%$ (16) apresentaram o conceito de 'educação política'. Majoritariamente, a concepção de educação política na saúde está associada à ideia de cidadania e contraditoriamente trabalha com as perspectivas críticas da educação. Como conclusão, os autores entendem que os conceitos de educação política foram considerados reduzidos em termos qualitativos, mas esta revisão ajuda a traçar caminhos na direção de um pensamento mais crítico sobre a educação política considerando a saúde como um direito social em uma sociedade capitalista. Para Carnut e Oliveira, desde o "golpe" de Estado de 2016 no Brasil, a discussão sobre a educação política retornou à cena educacional com muita força, especialmente no âmbito da saúde com a aceleração do desmonte do Sistema Único de Saúde (SUS).

Na sequência, Alexey Carvalho e Maria Márcia Sigrist Malavasi analisam a "Avaliação e acreditação da educação superior na América Latina e Caribe". Para os autores, no contexto da América Latina e Caribe, há uma diversidade de Instituições de Educação Superior (IES) e de sistemas de avaliação e acreditação. No artigo, analisam os sistemas de avaliação e 
acreditação de oito países, buscando entender como se configuram seus instrumentos de avaliação institucional e de cursos, seus estágios de maturidade, suas relações com as políticas públicas de seus respectivos países, bem como, aspectos relativos à valorização da autoavaliação e do contexto institucional. $\mathrm{O}$ estudo abrangeu uma pesquisa bibliográfica e documental, tendo como base os documentos, legislações e informações oficiais dos organismos de avaliação e acreditação de cada país pesquisado, e uma pesquisa de campo, com professores e pesquisadores em atividade nessas localidades, no intuito de captar as percepções acerca desses sistemas em cada realidade. A pesquisa contou com respondentes de oito países: Brasil, Chile, Colômbia, Equador, México, Peru, Uruguai e Venezuela Foi possível observar que apesar de haver uma grande diversidade e formatos de sistemas de avaliação e acreditação, há processos muito semelhantes em alguns deles, assim como ficou evidente um anseio dos respondentes no sentido de que os sistemas avancem para que haja uma contribuição efetiva na melhoria da qualidade. Os resultados da análise dos documentos e das percepções colhidas na pesquisa de campo, demonstraram, segundo os autores, que é preciso que os sistemas de avaliação e acreditação superem os aspectos burocráticos de verificação de conformidade e busquem avaliações formativas, que valorizem a autoavaliação e a pertinência das Instituições de Educação Superior e cursos, de forma a alimentar uma cultura de qualidade e melhoria contínua.

Iniciando a seção Relato de experiências, temos o texto "Oficina de língua portuguesa: memorial de leituras no ensino superior" de Daniervelin Renata Pereira. Este trabalho apresenta uma experiência vivenciada em uma turma introdutória do curso de Letras na disciplina presencial "Oficina de Língua Portuguesa", ofertada pela Faculdade de Letras da Universidade Federal de Minas Gerais em 2017. Essa experiência se deu no contexto de ensino-aprendizagem de língua portuguesa no ensino superior em torno da produção de memoriais sobre a aprendizagem da leitura. Para o relato, foram apresentados alguns conceitos que embasaram as práticas pedagógicas, tais como: modelos de leitura, leitura da "palavramundo", Pedagogia dos multiletramentos, memória e Recursos Educacionais Abertos. Os resultados dessa experiência, segundo a autora, remetem à importância de um trabalho didático com questões específicas da leitura e da escrita que envolva o engajamento dos graduandos em atividades colaborativas e dinâmicas, relacionando inteligível e sensível.

Tatiane da Silva Evangelista nos brinda com um "Relato de experiência: cálculo em quadrinhos". Evangelista questiona se há cálculo em quadrinhos e segue afirmando que é notório que em aulas ministradas exclusivamente nas formas tradicionais e expositivas o discente se disperse e não fique estimulado a aprender. Dessa forma, segundo a autora, aumentam as pesquisas no estudo da mudança do comportamento do aluno em relação ao seu processo de aprendizagem. Considerando esse aspecto, o presente trabalho tem por objetivo relatar como é possível usar histórias em quadrinhos em uma turma de disciplina obrigatória, Cálculo, do curso de Engenharias da Universidade de Brasília do campus Gama, na tentativa de aproximar o aluno do conteúdo, motivar o aprendizado e tornar o ambiente da sala de aula mais próximo e mais atrativo ao estudante. No final da sequência didática, foi aplicado um questionário para que o estudante pudesse avaliar a experiência. Na avaliação realizada pelos 
discentes concluiu-se, segundo Tatiane, que o universo das tirinhas, no ensino de Cálculo tornou o estudo mais significativo, descontraído e eficaz.

Adevailton Bernardo Santos faz um relato sobre "Educar pela pesquisa na formação inicial de professores". A problemática que se coloca é a dificuldade de formar professores que superem a mera reprodução de informações, muitas dentro de um contexto clássico, e passem a utilizar metodologias que incentivem os estudantes a uma formação pautada na pesquisa. Este texto relata atividades didáticas, em um curso superior de formação inicial de professores, alinhadas na proposta de "educar pela pesquisa", e os resultados de uma pesquisa realizada neste contexto com objetivo de buscar entender as concepções dos estudantes sobre estas atividades e as perspectivas futuras de seu uso. Os resultados, segundo o autor, indicam que os licenciandos passaram a ter uma visão diferenciada sobre o uso da pesquisa na educação básica, e veem de modo positivo a possibilidade de utilizarem atividades semelhantes na prática futura. A análise final mostra, para Santos, uma avaliação positiva das atividades realizadas e aponta para o fato de que os futuros docentes têm perspectivas melhores de utilizar e realizar a pesquisa em suas futuras práticas docentes quando ela permeia seu processo de formação.

Lidia Cristina Vilela Ribeiro e Márcio Renê Brandão Soussa nos traz um "Relato de experiências exitosas na iniciação científica: o uso da interdisciplinaridade e do trabalho em equipe". Este estudo teve por objetivos relatar e refletir sobre duas experiências interdisciplinares na iniciação científica, desenvolvidas em conjunto por dois docentes que atuam em áreas distintas do conhecimento (saúde e tecnologia), em uma Instituição de Ensino Superior. Trata-se de uma pesquisa que descreve a trajetória metodológica dos projetos orientados, nos anos de 2015 e 2018. Discute-se a relação da integração e articulação ocorrida entre os docentes e, destes, com os discentes das duas áreas. Os produtos obtidos desta parceria, segundo os autores, isto é, um atlas digital para o estudo de tecidos e um jogo educativo sobre a esquistossomose, do tipo serious game, demonstram a importância do desenvolvimento de trabalhos colaborativos e interdisciplinares na promoção de trocas de experiências, informações, desenvolvimento de habilidades e criação de ferramentas educativas que atendam às demandas de inovação tecnológica da educação contemporânea no ensino superior.

Ivan Fortunato nos traz um debate sobre "Práticas Pedagógicas no ensino superior: relato de experiência com a disciplina didática em licenciaturas". Este ensaio foi escrito com o objetivo de promover uma reflexão sobre alguns elementos da complexa atividade de lecionar no ensino superior. Dentre várias possibilidades, a Didática foi eleita como elemento central do texto, pois é muitas vezes entendida como a principal atividade da docência. Para desenvolver as ideias, duas experiências distintas com a condução da disciplina Didática, nomeadas como situações iceberg, foram tomadas como exemplo. O ensaio desdobra-se em duas seções: primeiro, identifica-se três elos entre as duas experiências, sendo o local, o docente e a disciplina de Didática; segundo, a partir desses elos, os elementos mais fundamentais de cada situação são evidenciados por meio de uma descrição investigativa. Ao final, segundo Fortunato, espera-se que o material aqui colhido da própria experiência se torne objeto de aprendizado para outras reflexões e inflexões, mas tenha a serventia de manter vivas as inquietações a respeito do ensino superior. 
Na secção Resenha Diego Palmeira Rodrigues e Silmara Terezinha Freitas vão discutir o conteúdo do Livro na modalidade coletânea, organizado por Maria de Lourdes Pinto de Almeida, Altair Alberto Fávero e Afrânio Mendes Catani, intitulado "O espaço europeu de educação superior (EEES) para além da Europa: apontamentos e discussões sobre o chamado processo de Bolonha e suas influências". Segundo Rodrigues e Freitas, discutir o Espaço Europeu de Educação Superior (EEES) e o Processo de Bolonha é muito importante para compreendermos a dinâmica de como este processo influencia mudanças e reformas na Educação Superior nas demais regiões do mundo. Para o caso específico de como a influência desse processo se desenvolve no ensino superior da América Latina, realidade na qual estamos inseridos, se torna ainda mais importante conhecer a visão de pesquisadores de diferentes países latino-americanos sobre as repercussões deste processo. É neste sentido que foi elaborada a obra "O espaço europeu de educação superior (EEES) para além da Europa: apontamentos e discussões sobre o chamado processo de Bolonha e suas influências", publicada pela Editora CRV (Brasil) em coedição com a Editora CLACSO (Argentina), em agosto de 2015. O livro tem o objetivo de, segundo os próprios organizadores, por meio de 9 capítulos, apresentar diferentes pontos de vista sobre os impactos do Processo de Bolonha na educação Superior da América Latina. Para tanto os capítulos tecem discussões sobre o papel da educação superior latino-americana frente à conformação do EEES decorrente do Processo de Bolonha.

Angela Gumieiro resenha o livro "Revolucionando a docência universitária: orientações, experiências e teorias para a prática docente em negócios", organizado pelos professores Gilberto José Miranda, Edvalda Araújo Leal e Silvia Pereira de Castro Casa Nova, e publicado em 2018. Com o objetivo de abordar temas relacionados à formação docente para o ensino universitário, no que se refere à metodologia do ensino superior em negócios. Composto por doze capítulos divididos em três partes, que abordam diferentes dimensões da docência universitária, propondo refletir e aproximar o extenso e rico material humano e de pesquisa sobre docência superior na área de negócios.

Michele Luciane Blind de Morais vai nos brindar com resenha do livro de Lucídio Bianchetti, Antônio Álvaro Soares Zuin e Obdália Santana Ferraz Silva, intitulado "Publique, apareça ou pareça: produtivismo acadêmico, pesquisa administrativa e plágio nos tempos da cultura digital". O livro, escrito a seis mãos, resultado de uma trama de ideias sobre a temática publique, pereça ou apareça, traz uma reflexão sobre os efeitos das transformações pelas quais passa a pós-graduação stricto sensu em termos de produção e veiculação/socialização do conhecimento.

Como podem perceber este volume traz textos densos com temas atuais e extremamente pertinentes a área da Educação Superior no território ibero-americano. Nada mais nos resta a não ser desejar lhes uma profícua leitura!

Campinas, abril de 2020.

Os editores 


\section{REFERÊNCIAS}

MOREIRA, C. R. B. S.; SILVA, P. V. B. DA. Ações afirmativas fazem diferença? . Revista Internacional de Educação Superior, v. 6, p. e020001, 24 maio 2019.

TIECHER, A. L.; FIALHO, D. DA M.; ENS, R. T. Formação do professor para a educação superior em eventos nacionais (2014-2016). Revista Internacional de Educação Superior, v. 6, p. e020002, 31 maio 2019.

REIS, G. M. DOS; ANDRADE, M. DE F. R. DE. As parcerias informais e o desenvolvimento profissional docente no ensino superior. Revista Internacional de Educação Superior, v. 6, p. e020003, 31 maio 2019.

SOARES, S. A. DA S.; PAULY, E. L.; FOSSATTI, P. As/ os secretárias/os de programas de pós- graduação stricto e sua relação com a internacionalização. Revista Internacional de Educação Superior, v. 6, p. e020009, 21 jun. 2019.

BARBOSA, P. L. S.; SILVA, R. DA; SOUSA, R. A. DE. Compreensão do uso de desenhos no processo de ensino aprendizagem para alunas do curso informatização. Revista Internacional de Educação Superior, v. 6, p. e020012, 11 out. 2019.

KICH, J. I. D. F. Blended learning na prática. R Revista Internacional de Educação Superior, v. 6, p. e020014, 13 set. 2019.

RAMOS, G. P.; ROTHEN, J. C.; FERNANDES, M. C. DA S. G. Mecanismos de avaliação e regulação da Universidade Federal Brasileira no REUNI. Revista Internacional de Educação Superior, v. 6, p. e020015, 19 set. 2019.

EISENBACH NETO, F. J.; BONETI, L. W. Sistema econômico internacional, ideologia e ensino superior brasileiro. Revista Internacional de Educação Superior, v. 6, p. e020016, 19 set. 2019.

FREITAS, M. C. DE; GIL, C. A. Envelhecimento e trabalho. Revista Internacional de Educação Superior, v. 6, p. e020018, 18 set. 2019.

MELO, S. P.; BRAGA, O. R.; SANTANA, J. F. Juventude rural e ensino superior público. Revista Internacional de Educação Superior, v. 6, p. e020022, 16 out. 2019.

RADETZKE, F. S.; GÜLLICH, R. I. DA C. As pesquisas sobre a docência no ensino superior em contexto brasileiro. Revista Internacional de Educação Superior, v. 6, p. e020024, 29 out. 2019.

GRISA, G. D.; NEVES, C. E. B.; RAIZER, L. Percursos acadêmicos de estudantes cotistas. Revista Internacional de Educação Superior, v. 6, p. e020026, 28 out. 2019.

BITTENCOURT, R. L. DE; SILVA, R. G. DA. Contribuições da pesquisa para o desenvolvimento profissional docente na perspectiva dos coordenadores dos cursos de licenciatura. Revista Internacional de Educação Superior, v. 6, p. e020027, 29 out. 2019. 
MELlO NETO, R. DE D. E; MEDEIROS, H. A. V.; CATANI, A. M. ProUni e retornos de capitais para instituições privadas de ensino superior. Revista Internacional de Educação Superior, v. 6, p. e020028, 30 out. 2019.

LUZ, S. V. DA; MOREIRA, H. A aquisição de habilidades didático-pedagógicas de professores do ensino superior. Revista Internacional de Educação Superior, v. 6, p. e020029, 5 nov. 2019.

FINARDI, K. R.; GUIMARÃES, F. F.; MENDES, A. R. Pensando a internacionalização (crítica) do ensino superior brasileiro. Revista Internacional de Educação Superior, v. 6, p. e020031, 7 nov. 2019.

TREVISOL, J. V.; BASTIANI, S. C. D. O cinquentenário da educação superior no oeste de Santa Catarina. Revista Internacional de Educação Superior, v. 6, p. e020032, 28 nov. 2019.

SILVA, R. B. E; CONCEIÇÃO, V. K. P. DA. O comitê de ética em pesquisa como espaço de formação continuada do professor universitário. Revista Internacional de Educação Superior, v. 6, p. e020033, 4 dez. 2019.

HABOWSKI, A. C.; CONTE, E. Reprodução de gênero pela cinematografia. Revista Internacional de Educação Superior, v. 6, p. e020035, 5 dez. 2019.

SANTOS JUNIOR, J. DA S.; REAL, G. C. M. Fator institucional para a evasão na educação superior. Revista Internacional de Educação Superior, v. 6, p. e020037, 27 dez. 2019.

CERUTTI, E. Tecendo saberes sobre as tecnologias assistivas para o sujeito surdo no ensino superior. Revista Internacional de Educação Superior, v. 6, p. e020040, 20 fev. 2020.

GULKA, J. A.; LUCAS, E. R. DE O. O papel educativo das bibliotecas universitárias. Revista Internacional de Educação Superior, v. 6, p. e020041, 27 fev. 2020.

SILVA, C. F. DA; LOPES, R. DE M.; OLIVEIRA, A. A agenda de pesquisa em sociologia da educação na pós-graduação brasileira. Revista Internacional de Educação Superior, v. 6, p. e020044, 11 mar. 2020.

MACHADO, K. G. W.; KAMPFF, A. J. C. Educação superior. Revista Internacional de Educação Superior, v. 6, p. e020045, 2 abr. 2020.

LIEBL, K. R.; LIMA, I. G. DE; PINTO, M. M. Avaliações em larga escala e educação especial. Revista Internacional de Educação Superior, v. 6, p. e020004, 31 maio 2019.

FRITSCH, R.; VITELLI, R. F.; ROCHA, C. S. A evasão em disciplinas de cursos de graduação. Revista Internacional de Educação Superior, v. 6, p. e020005, 31 maio 2019.

MARQUEZAN, L. P.; SAVEGNAGO, C. L. O mestrado profissional no contexto da formação continuada e o impacto na atuação dos profissionais da educação. Revista Internacional de Educação Superior, v. 6, p. e020011, 12 set. 2019. 
CIRÍACO, K. T.; SILVA, A. C. DA. Entre "sobrevivências" e "descobertas\&quot; . Revista Internacional de Educação Superior, v. 6, p. e020017, 26 set. 2019.

IZQUIERDO, I.; ESTRADA, O. N. Experiências de migração de acadêmicas sul-americanas em duas universidades públicas mexicanas. Revista Internacional de Educação Superior, v. 6, p. e020021, 11 out. 2019.

QUIROGA, S. R. Alunos e internacionalização. Revista Internacional de Educação Superior, v. 6, p. e020023, 18 out. 2019.

SILVA, R. S. DA; NOVELlO, T. P. O uso das tecnologias digitais no ensinar matemática. Revista Internacional de Educação Superior, v. 6, p. e020025, 23 out. 2019.

PERATZ, T.; PORTELINHA, A. M. S. A organização do trabalho pedagógico no Instituto Federal e as implicações para o trabalho docente. Revista Internacional de Educação Superior, v. 6, p. e020030, 5 nov. 2019.

GONÇALVES, L. H.; ZUIN, D. C. O sistema de saúde na assistência estudantil da UFV. Revista Internacional de Educação Superior, v. 6, p. e020034, 5 dez. 2019.

BRITO, C. E.; FERASSO, M.; BRITO, S. M. P. P. L. E. A gestão dos cursos EAD em Moçambique. Revista Internacional de Educação Superior, v. 6, p. e020036, 27 dez. 2019.

MARTINS, F. B.; ROCHA, H. P. A. DA; COSTA, F. R. DA. Uma revisão narrativa sobre o estudante-atleta no ensino superior. Revista Internacional de Educação Superior, v. 6, p. e020038, 17 jan. 2020.

CARNUT, L.; OLIVEIRA, R. A. DE. Educação política nas bases de dados na área da saúde. Revista Internacional de Educação Superior, v. 6, p. e020042, 27 fev. 2020.

CARVALHO, A.; MALAVASI, M. M. S. Avaliação e acreditação da educação superior na América Latina e Caribe. Revista Internacional de Educação Superior, v. 6, p. e020043, 9 mar. 2020.

PEREIRA, D. R. Oficina de língua portuguesa. Revista Internacional de Educação Superior, v. 6, p. e020006, 4 fev. 2019.

EVANGELISTA, T. DA S. Relato de experiência. Revista Internacional de Educação Superior, v. 6, p. e020007, 30 maio 2019.

SANTOS, A. B. Educar pela pesquisa na formação inicial de professores. Revista Internacional de Educação Superior, v. 6, p. e020013, 13 set. 2019.

RIBEIRO, L. C. V.; SOUSSA, M. R. B. Relato de experiências exitosas na iniciação científica. Revista Internacional de Educação Superior, v. 6, p. e020020, 25 set. 2019.

FORTUNATO, I. Práticas pedagógicas no ensino superior. Revista Internacional de Educação Superior, v. 6, p. e020039, 7 fev. 2020.

\begin{tabular}{l|c|c|c|c|c} 
(C) Rev. Inter. Educ. Sup. & Campinas, SP & v.6 & $1-15$ & e020046 & 2020 \\
\hline
\end{tabular}


RODRIGUES, D. P.; FREITAS, S. T. O espaço europeu de educação superior (EEES) para além da Europa. Revista Internacional de Educação Superior, v. 6, p. e020008, 24 maio 2019.

GUMIEIRO, A. Revolucionando a docência universitária. Revista Internacional de Educação Superior, v. 6, p. e020010, 26 jun. 2019.

MORAIS, M. L. B. DE. Publique, apareça ou pareça. Revista Internacional de Educação Superior, v. 6, p. e020019, 20 set. 2019. 